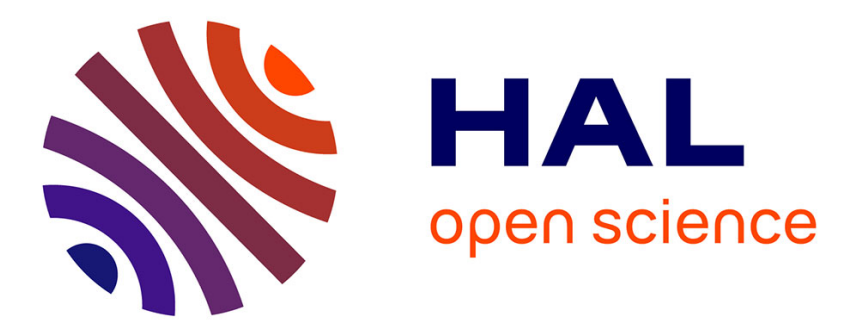

\title{
North Atlantic and Pacific Quasi-Stationary Parts of Atmospheric Rivers and Their Implications for East Asian Monsoon Onset
}

\author{
H.-I. Lee, J.L. Mitchell, A. Tripati, J.M. Lora, G. Chen, Q. Ding
}

\section{- To cite this version:}

H.-I. Lee, J.L. Mitchell, A. Tripati, J.M. Lora, G. Chen, et al.. North Atlantic and Pacific QuasiStationary Parts of Atmospheric Rivers and Their Implications for East Asian Monsoon Onset. Geophysical Research Letters, 2019, 46 (21), pp.12311-12320. 10.1029/2019GL084272 . hal-02944474

\author{
HAL Id: hal-02944474 \\ https://hal.science/hal-02944474
}

Submitted on 9 Apr 2021

HAL is a multi-disciplinary open access archive for the deposit and dissemination of scientific research documents, whether they are published or not. The documents may come from teaching and research institutions in France or abroad, or from public or private research centers.
L'archive ouverte pluridisciplinaire HAL, est destinée au dépôt et à la diffusion de documents scientifiques de niveau recherche, publiés ou non, émanant des établissements d'enseignement et de recherche français ou étrangers, des laboratoires publics ou privés. 


\section{Geophysical Research Letters}

\section{RESEARCH LETTER \\ 10.1029/2019GL084272}

\section{Special Section:}

Atmospheric Rivers: Intersection of Weather and Climate

\section{Key Points:}

- North Atlantic and Pacific atmospheric rivers have quasi-stationary parts in subtropical latitudes that evolve along predictable paths

- The quasi-stationary part of the Pacific atmospheric river foretells onset of the East Asian Summer Monsoon a month before it occurs

- Our discovery opens up a new avenue of onset prediction in subtropical monsoon extension regions

Supporting Information:

- Supporting Information S1

Correspondence to:

H.-I. Lee,

hilee@atmos.ucla.edu

\section{Citation:}

Lee, H-I., Mitchell, J. L., Tripati, A., Lora, J. M., Chen, G., \& Ding, Q. (2019). North Atlantic and Pacific quasi-stationary parts of atmospheric rivers and their implications for East Asian monsoon onset. Geophysical Research Letters, 46, 12,311-12,320. https://doi.org/10.1029/2019GL084272

Received 24 JUN 2019 Accepted 12 SEP 2019 Accepted article online 16 OCT 2019 Published online 5 NOV 2019

(2)219. American Geophysical Union. All Rights Reserved.

\section{North Atlantic and Pacific Quasi-Stationary Parts of Atmospheric Rivers and Their Implications for East Asian Monsoon Onset}

\author{
Hung-I Lee ${ }^{1}\left(\mathbb{D}\right.$, Jonathan L. Mitchell ${ }^{1,2} \mathbb{D}$, Aradhna Tripati ${ }^{1,2,3,4}$, Juan M. Lora $^{2,5}$, Gang Chen $^{1} \mathbb{D}$, \\ and Qinghua Ding ${ }^{6,7}$ iD \\ ${ }^{1}$ Department of Atmospheric and Oceanic Sciences, University of California, Los Angeles, CA, USA, ${ }^{2}$ Department of \\ Earth, Planetary, and Space Sciences, University of California, Los Angeles, CA, USA, ${ }^{3}$ Institute of the Environment and \\ Sustainability, University of California, Los Angeles, CA, USA, ${ }^{4}$ European Institute of Marine Sciences (IUEM) \\ Universit de Brest, UMR 6538, Domaines Ocaniques, Rue Dumont D'Urville, and IFREMER, Plouzan, France, \\ ${ }^{5}$ Department of Geology and Geophysics, Yale University, New Haven, CT, USA, ${ }^{6}$ Department of Geography, University \\ of California, Santa Barbara, CA, USA, ${ }^{7}$ Earth Research Institute, University of California, Santa Barbara, CA, USA
}

\section{Introduction}

Once envisioned as a local, large-scale sea-breeze driven by land-sea contrasts in surface heating (Webster, 1987; Webster \& Fasullo, 2003), consensus is emerging that regime transitions in the (Hadley) overturning circulation govern monsoon onset (Bordoni \& Schneider, 2008; Schneider \& Bordoni, 2008). However, regional-scale zonal asymmetry_for instance, the Tibetan Plateau (Boos \& Kuang, 2010) and the West Pacific Subtropical High (Wang et al., 2013) —are also important for the East Asian Summer Monsoon (EASM). The dynamics of seasonally transitioning Hadley circulations have been well studied under zonally symmetric climate forcing (Emanuel, 1995; Fang \& Tung, 1999; Faulk et al., 2017; Lindzen \& Hou, 1988; Plumb \& Hou, 1992; Schneider \& Bordoni, 2008; Walker \& Schneider, 2006). However, zonal asymmetries of the Intertropical Convergence Zone (ITCZ) in the East Asian and North American monsoon sectors, which feature the local extensions of rain-belts into midlatitudes, indicate that the zonally symmetric perspective is incomplete. Several recent studies attribute the asymmetric ITCZ to zonally asymmetrical forcing induced by topography of the Tibetan Plateau or the Rocky Mountains (Geen et al., 2018; Shaw \& Voigt, 2016). The influence of the land is attributed to the "insulating" effect of the Tibetan Plateau (Boos \& Kuang, 2010), topographic stationary waves (Geen et al., 2018; Shaw \& Boos, 2012; Shaw \& Voigt, 2016), or diabatic heating induced by low continental albedo (Kelly \& Mapes, 2013).

The ocean's role in monsoon onset is a matter of ongoing debate. The West Pacific Subtropical High, which itself has moderate predictability, is strongly correlated with the intensity of the EASM (Wang et al., 2013). Waves propagating westward and originating from ocean basins appear to trigger onset in simulations, indicating a possible role for zonally asymmetric ocean circulations (Xie \& Saiki, 1999), and this view has further been developed (Privé \& Plumb, 2007) with waves propagating from the ocean being suggested to delay rather than trigger the onset. Ventilation of low moist static energy air from neighboring, cold waters may ultimately halt poleward progression of the monsoon (Chou \& Neelin, 2003), but this mechanism is not predictive of onset timing. Also, warming oceans under climate change will likely stabilize the troposphere, providing an enhanced convective barrier over land that ultimately delays monsoon onset (Seth et al., 2013). 
We take a purely empirical approach to investigate the mechanisms that link ocean basins with monsoon onset. Using a longitude-time Hovmöller diagram of column water vapor (CWV) at $30^{\circ} \mathrm{N}$ in daily ERA-Interim reanalysis (Dee et al., 2011), we identify regions of enhanced CWV in the Pacific and Atlantic Ocean basins that coincide with the climatological crossing points of quasi-stationary atmospheric rivers at $30^{\circ} \mathrm{N}$; we term these quasi-stationary parts of atmospheric rivers (QSARs). We identify QSARs in the Hovmöller diagrams of CWV in section 2 and clarify their phenomonological patterns in section 3 . We compare with the EASM onset index in section 4 and quantify the influence of El Niño-Southern Oscillation (ENSO) in section 5. In section 6, we connect QSARs with fronts of synoptic wave breakings and discuss a plausible mechanism of QSAR generation.

\section{QSAR: Zonally and Seasonally Migrating Local CWV Maxima in the Pacific/Atlantic}

We show a global longitude-time (Hovmöller) plot of CWV at $30^{\circ} \mathrm{N}$ in 2017 using daily mean ERA-Interim reanalysis in Figure 1a. Thirty degrees north was particularly chosen to investigate the extensions of monsoons outside typical ITCZ migrations and further into the subtropics, especially in East Asia. Several types of CWV patterns could be found in Figure 1a: summer (mid-June-mid-October) CWV enhancement in the Pacific $\left(120^{\circ} \mathrm{E}-120^{\circ} \mathrm{W}\right)$ and Atlantic $\left(90-10^{\circ} \mathrm{W}\right)$, low CWV values especially at the Tibetan Plateau $\left(80-100^{\circ} \mathrm{E}\right)$ and Rocky Mountains $\left(105-110^{\circ} \mathrm{W}\right)$ for the entire year (as illustrated in Figure 1a), a series of synoptic eastward-propagating waves (pointed to by red arrows in Figure 1a) downstream of the Tibetan Plateau and Rocky Mountains during winter and spring (November-June), and two seasonally migrating bands with local, zonal maxima of CWV in both the Pacific and Atlantic basins (black-white curves in Figure 1a).

We now focus on the two seasonally migrating bands; these correspond to the QSARs (see section 3 for details). To identify the pathways of QSARs, it is insufficient to simply define discrete QSAR pathways as longitudes containing local CWV maxima within their own ocean basins because those maxima sometimes occur at synoptic eastward-propagating waves instead of QSARs. Hence, we develop a feature-tracking algorithm to find local CWV maxima in a given longitude range (see Appendix A for more details), with which we identify QSAR pathways (black/white curves in Figure 1a/2a). As shown in Figure 1a/2a, QSAR pathways emerge from eastern-central Pacific/Atlantic during wintertime (January to April) and then start to propagate westward (mid-April for Pacific QSAR/mid-May for Atlantic QSAR). The Pacific QSAR reaches the western boundary of the Pacific about the time of EASM onset (yellow stippling; see section 4 for details) and returns to the east roughly when EASM concludes.

QSARs exist but appear smoother in a 5-year (2012-2017) daily climatology of CWV (supporting information Figure S2). Even in the 39-year (1979-2017) climatological mean CWV at 30 N (Figure 2b), two QSARs can still be identified in the Pacific and Atlantic Ocean basins by applying the tracking algorithm on the 39-year climatological CWV, although they are less prominent compared to an individual year (Figure 2a) and 5-year climatological mean (Figure S2). The presence of QSARs in the long-term, daily climatology indicates that these features are quasi-stationary phenomena with a seasonal cycle. QSARs are also apparent in satellite CWV (Figure S3), for all latitudes between $25^{\circ} \mathrm{N}$ to $40^{\circ} \mathrm{N}$, albeit with slightly different pathways. This fact indicates that QSARs are involved in large-scale atmospheric flow spanning of $25^{\circ} \mathrm{N}$ to $40^{\circ} \mathrm{N}$.

\section{The QSAR}

We have so far phenomenologically described QSARs evolving from eastern-central Pacific/Atlantic, propagating westward in the winter and spring, and making landfall during the summer monsoon. We now demostrate the propagating nature of QSARs and clarify the relation to atmospheric rivers. Atmospheric rivers are the eastward-propagating extensions of CWV filaments from deep tropics to subtropics/midlatitudes and are associated with synoptic eastward-propagating waves (Payne \& Magnusdottir, 2014) in Hovmöller diagrams (illustrated by red arrows in Figure 1a). The eastward-propagating waves initiate downstream of the Tibetan Plateau and the Rocky Mountains and terminate at the Pacific/Atlantic QSARs, respectively, especially during wintertime. The waves that travel upstream of the Tibetan Plateau and terminate west of the Tibetan Plateau are beyond our major interests in this study.

The global northern hemispheric CWV maps on 16 January 2017 (Figure 1c) and 27 May 2017 (Figure 1b) have particularly prominent QSARs in each basin, and we choose these dates to avoid confusion between 


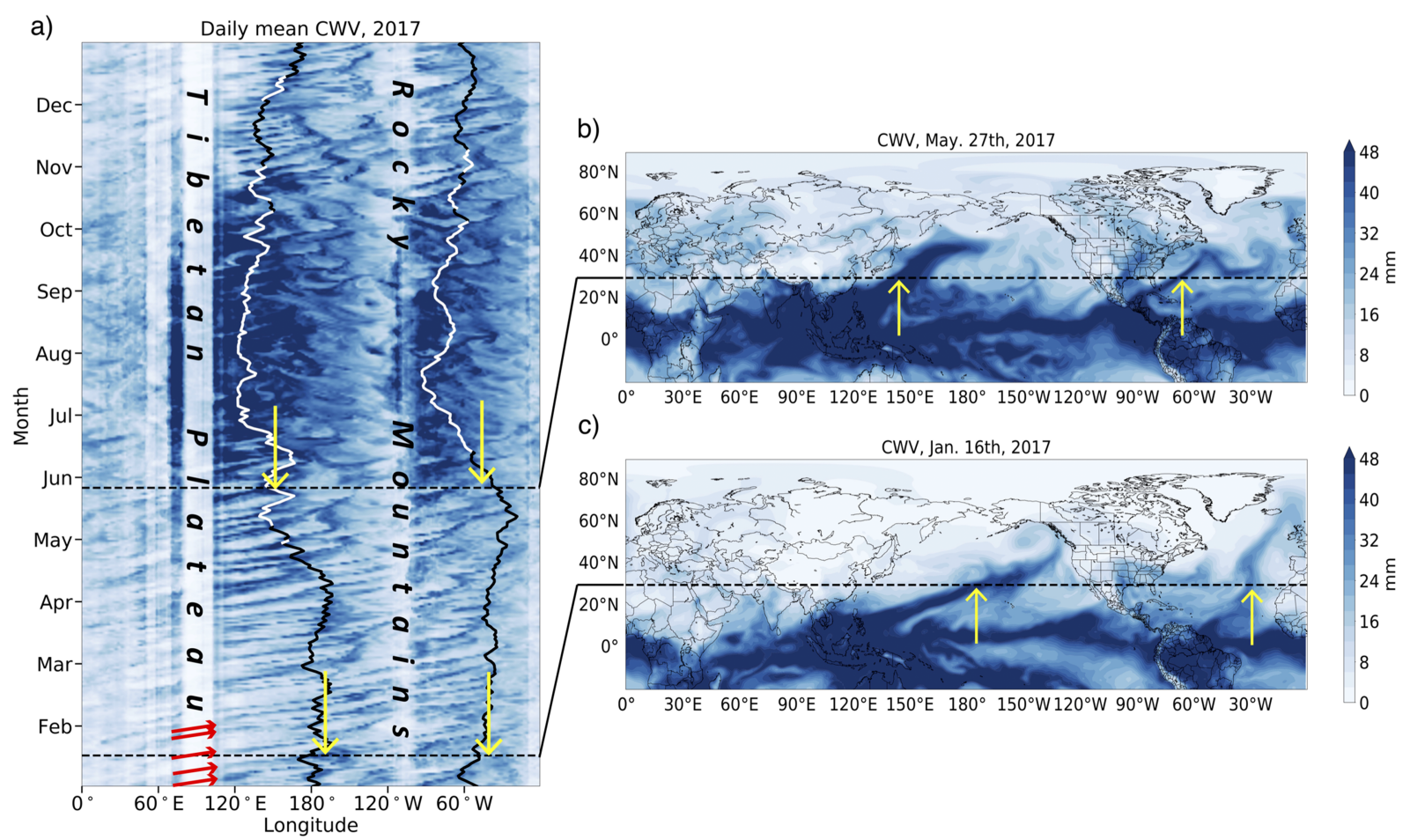

Figure 1. (a) Hovmöller diagram of CWV (2017) at 30 $\mathrm{N}$ with the addition of (1) QSAR pathways marked by white curves (with the amount of 7-day moving averaged CWV above $40 \mathrm{~mm}$ ) and black curve (below $40 \mathrm{~mm}$ ), (2) red arrows to illustrate synoptic westerly waves, and (3) two black dashed horizontal lines and yellow arrows to show the locations of QSARs on 27 May 2017 and 16 January 2017. (b) CWV map on 27 May 2017. The black dashed horizontal line shows $30^{\circ} \mathrm{N}$, and two yellow arrows indicate the locations of QSAR observed in (a). (c) Same as (b) but on 16 January 2017. LWA = local wave activity; $\mathrm{CWV}=$ column water vapor; $\mathrm{QSAR}=$ quasi-stationary parts of atmospheric rivers.

propagating synoptic waves and QSARs. The Hovmöller diagram (Figure 1a) shows that Pacific/Atlantic QSARs on 16 January 2017 are located near the dateline and $30^{\circ} \mathrm{W}$, respectively (marked by two yellow arrows on 16 January), where two crossing points at $30^{\circ} \mathrm{N}$ of the Pacific/Atlantic atmospheric rivers appear as the filaments containing high values of CWV extending toward midlatitudes in the CWV map plot for the same day (two yellow arrows in Figure 1c). Similarly, locations of Pacific/Atlantic QSARs on 27 May 2017 (marked by two yellow arrows on 27 May in Figure 1a) stay at crossing points of the Pacific/Atlantic atmospheric rivers at $30^{\circ} \mathrm{N}$ (two yellow arrows in Figure 1b). Therefore, QSARs are actually the crossing points of atmospheric rivers at $30^{\circ} \mathrm{N}$. Given that synoptic atmospheric rivers halt at QSARs, QSARs can be regarded as where synoptic atmospheric rivers become quasi-stationary and terminate their eastward propagation.

Recent studies discovered a southerly water vapor front with intense moisture delivery to East Asia (Pan et al., 2017; Renhe, 2001; Yao et al., 2013) during EASM seasons (Li et al., 2016; Yong \& Huang, 2019) and determined several ENSO-induced extreme events (Li \& Zhou, 2012). Atmospheric rivers also contribute to the intense moisture delivery (Kamae et al., 2017) with their variations in strength induced by EASM (Kamae et al., 2017; Mundhenk et al., 2016) and ENSO (Kamae et al., 2017) climatologically. Climate model simulations further indicate the roles of synoptic waves in monsoon onset (Privé \& Plumb, 2007; Xie \& Saiki, 1999). Hence, our study bridges the traditional view of southerly water fronts during EASM seasons with our discovery of QSARs due to the coincidence of QSARs with EASM onset in longitude-time Hovmöller diagrams from Figure 2.

\section{The Implications of QSAR to EASM Onset}

We articulate the link between QSARs and EASM onset by plotting a widely used empirical monsoon index (Wang, 2002) adopted in the IPCC report (IPCC, 2013) onto the Hovmöller diagram (Figures 2a and 2b). The index defines monsoon periods when a 5 -day moving averaged precipitation is $5 \mathrm{~mm} /$ day greater than January averaged precipitation for each location. In Figure 2b, the EASM region (marked by yellow stippling) 

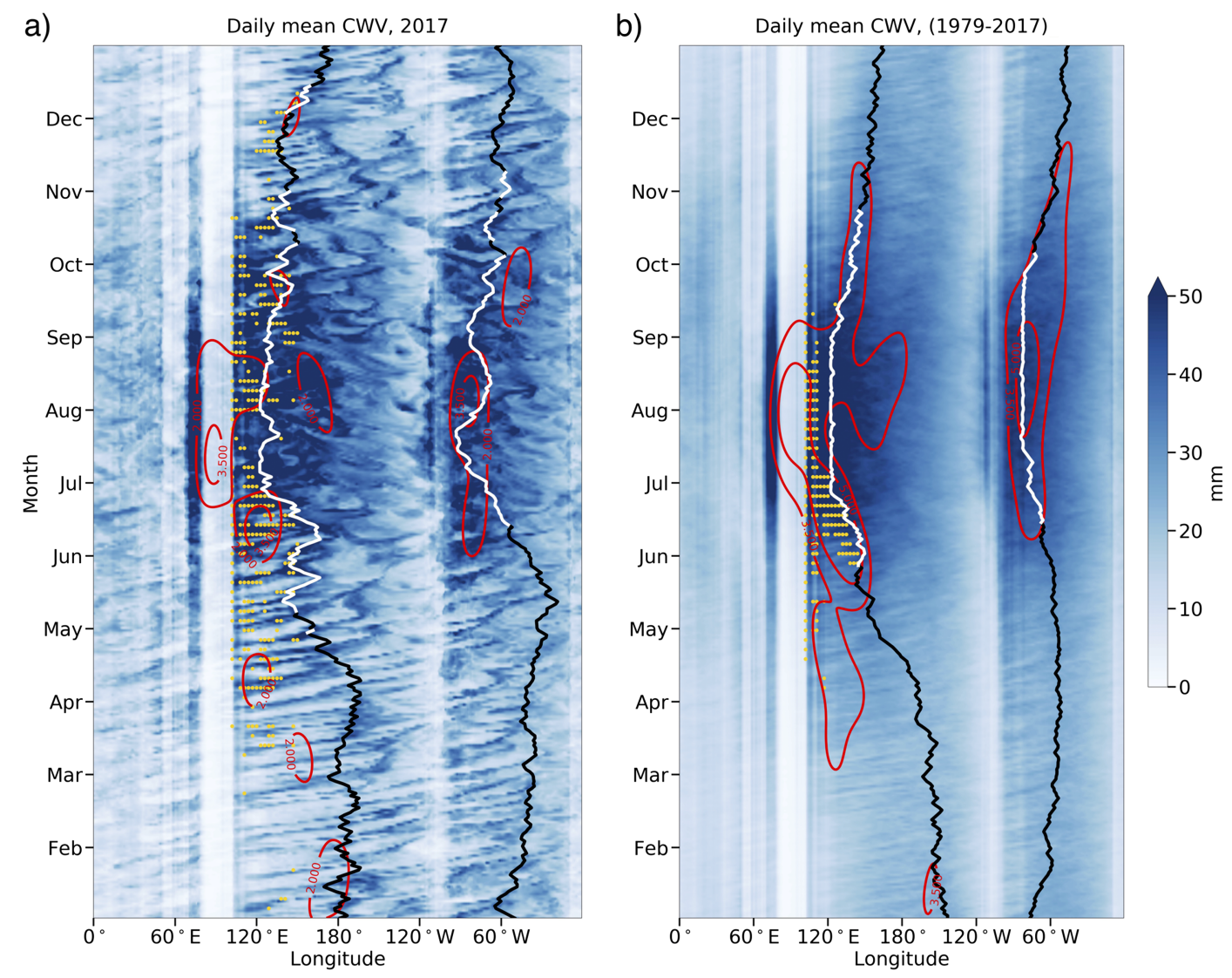

Figure 2. (a) Hovmöller diagram of column water vapor (CWV; 2017) at $30^{\circ} \mathrm{N}$ with the addition of quasi-stationary part of atmospheric rivers pathways marked by white curves (with the amount of 7-day moving averaged CWV above $40 \mathrm{~mm}$ ) and black curve (below $40 \mathrm{~mm}$ ). Yellow stippling indicates areas that satisfy the monsoon index, and the red contours are smoothed precipitation (mm/day). (b) Same as (a) but for 39-year (1979-2017) climatological mean.

evolves from the west Pacific (130-140 $\mathrm{E}$ ) in late May (on 31 May on average) gradually toward the East Asian continent $\left(100-110^{\circ} \mathrm{E}\right)$ in mid-June (on 11 June on average). Several early, individual extreme precipitation events occurring near the Tibetan Plateau in April and May also meet the monsoon index criteria, but here we ignore those events since they are outside our primary interests in this study.

The Pacific QSAR presented in Figure 2b coincides with the eastern edge of the EASM region when the monsoon onset occurs over the ocean and then propagates with the monsoon onto land. To better interpret the relation between QSARs and the monsoon index, we plot smoothed precipitation contours (red contour in Figure 2b) onto the Hovmöller diagrams (the technique we apply to smooth the precipitation contour is described in Figure S4). QSAR pathways with their 7-day moving averaged CWV above $40 \mathrm{~mm}$ (white curves in Figure 2b) roughly fit the $5 \mathrm{~mm} /$ day contour in the Pacific sector.

The coincidence between the $5 \mathrm{~mm} /$ day precipitation in monsoon regions and 40-mm CWV in composite Hovmöller plots strongly suggests that QSARs indicate moisture supply for precipitation over the areas through which they pass. This is perhaps expected, since at least tropical precipitation is tightly coupled to a threshold value of CWV (see Figure S5; Peters \& Neelin, 2006). Therefore, we define monsoon onset within the CWV data set to occur when the QSAR value first exceeds $40 \mathrm{~mm}$. In the 39-year climatology, the Pacific QSAR first exceeds $40 \mathrm{~mm}$ on 29 May at $144.6^{\circ} \mathrm{E}$, about the same time as the monsoon onset date (31 May) from the precipitation-based monsoon index used by the IPCC. Given that CWV fluctuates less than precipitation for individual years (Figure 2a), we use the 40-mm exceedance date for the discussion of year-to-year variability. 

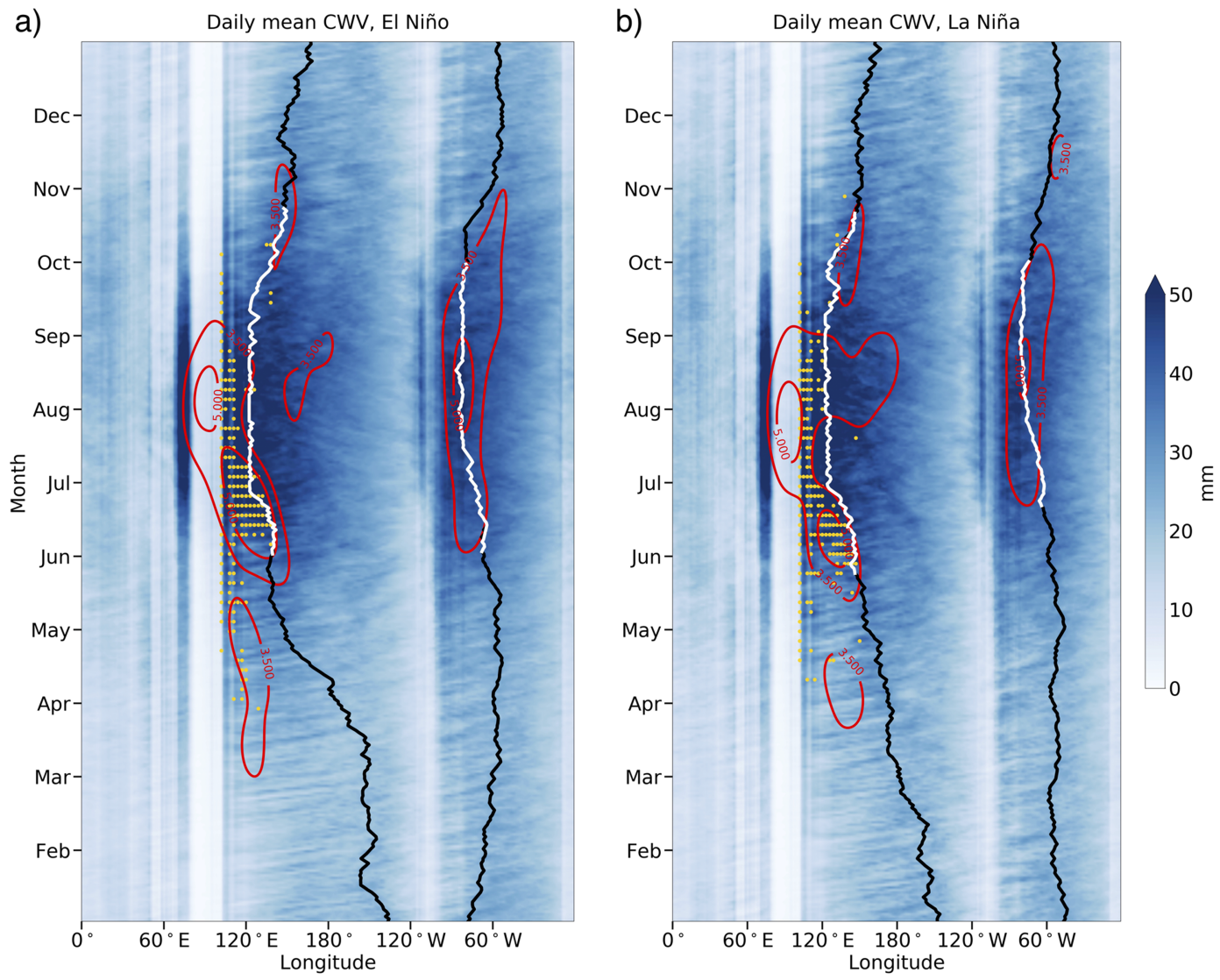

C)

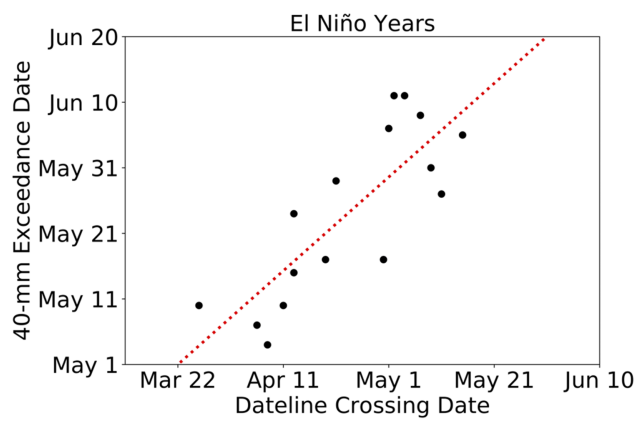

d)

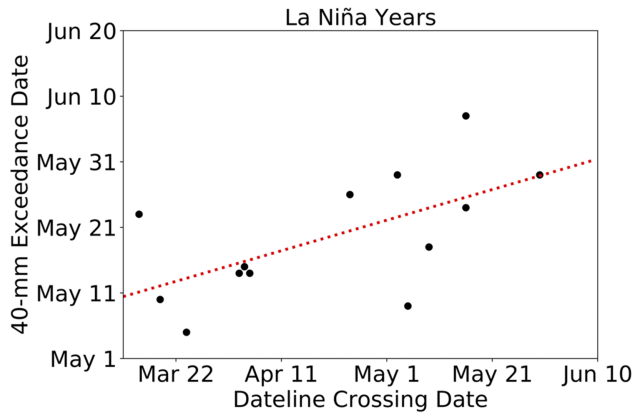

Figure 3. (a) Same as Figure 2 but for El Niño (decaying El Niño). (b) Same as (a) but for La Niña (decaying La Niña). Enclosed quasi-stationary part of atmospheric rivers pathways of El Niño/La Niña are not required unlike 5- and 39-year climatology (see Appendix A). (c) The scatter plot of 40-mm exceedance date of the quasi-stationary part of atmospheric river (our monsoon onset proxy) without an outlier in 1992, and the date when the zonal average of $30^{\circ} \mathrm{N}$ column water vapor (CWV) on $180-120^{\circ} \mathrm{W}$ is greater than $120^{\circ} \mathrm{E}-180^{\circ} \mathrm{W}$ (dateline crossing) during El Niño with the slope 0.71 , intercept 63 days, correlation coefficient 0.81 , and $p$ value 0.0002 by linear regression analysis. El Niño years here are selected when Niño 3.4 index in May is above 0.25. (d) Same as (c) but for La Niña with the slope 0.23, intercept 113 days, correlation coefficient 0.61 , and $p$ value 0.026. La Niña years here are selected when Niño 3.4 index in May is below -0.25 .

\section{QSAR Variability and EASM Onset Prediction}

As might be expected, QSAR seasonal pathways are sensitive to Pacific climate variability, particularly ENSO. Hovmöller diagrams for El Niño and La Niña composite CWV are presented in Figures $3 \mathrm{a}$ and $3 \mathrm{~b}$ with the lists of ENSO years given in Table S2. During El Niño conditions, monsoon area, precipitation, and QSARs behave similarly compared to the 39-year daily climatology. However, QSARs during La Niña years are more centrally located in the Pacific, while during El Niño and in the climatology, QSARs begin in the winter in the east Pacific and traverse a larger distance westward. Climatologically, QSARs reach $40 \mathrm{~mm}$ on 26 May 
$\left(143.4^{\circ} \mathrm{E}\right)$ during La Niña and on 3 June $\left(136.4^{\circ} \mathrm{E}\right)$ during El Niño. These dates are also consistent with the monsoon onset dates, on 23 May for La Niña and on 7 June for El Niño, obtained from the IPCC precipitation index. Therefore, we conclude that CWV QSARs are consistent with the earlier/delayed EASM onsets during El Niño/La Niña states, and this result is consistent with studies of climatological EASM onsets under the influence of ENSO states (Ju \& Slingo, 1995; Lau \& Nath, 2003; Tanaka, 1997; Wu \& Wang, 2000; Wu et al., 2009).

Similar analysis of individual-year precipitation to identify monsoon onset dates using the IPCC precipitation index fails because daily precipitation variability is similar in magnitude to the $5 \mathrm{~mm}$ /day threshold. To identify the monsoon onset date for each year, several techniques have been developed. These include filtering the raw data using empirical orthogonal functions (Wang et al., 2004) and averaging large areas of precipitation data (Zhou \& Chan, 2007; Zhang et al., 2002), but these monsoon indices mask the fine spatiotemporal structures of the EASM. In contrast, the pathways of the QSARs and their 40-mm CWV threshold can be identified for each individual year; Figure 2a shows the QSAR pathway for 2017, which has a 40-mm exceedance date of 10 May. Because of the strong dependence of precipitation on CWV (Figure S5), we propose to use 40-mm exceedance dates of the Pacific QSARs as a proxy of EASM onset; we perform the same technique to generate QSAR pathways during individual years and summarize 40-mm exceedance dates of QSARs for the past 39 years in Table S2.

We now offer a simple forecasting metric with predictive skill for the EASM onset during individual years by utilizing the passage of the Pacific QSAR across the dateline. However, Pacific QSARs might travel back-and-forth along the dateline (Figure 2a) given the strong influence of synoptic westerly waves. To avoid this ambiguity, we define the dateline crossing date by requiring the mean CWV at $30^{\circ} \mathrm{N}$ and $120^{\circ} \mathrm{E}-180^{\circ} \mathrm{W}$ to be greater than at $180-120^{\circ} \mathrm{W}$ and for the difference to exceed three standard deviations of the historical W-E Pacific CWV difference without a climatological seasonal cycle (see Text S3). This quantity is readily calculable for each individual year and is summarized in Table S2. The correlation coefficient between 40-mm exceedance date and dateline crossing of the QSAR for all years is 0.51 ( $p$ value 0.001; see Figure S6b), which indicates our simple CWV metric has some skill in predicting the onset of the EASM.

Figure 3c/3d show scatter plots and linear regressions between $40-\mathrm{mm}$ exceedance date and dateline crossing of the Pacific QSARs in years following El Niño/La Niña (Niño 3.4 greater/less than 0.25 in May). With this ENSO-based separation, high correlation coefficients and low $p$ values indicate that ENSO indeed governs the QSAR pathways and the subsequent monsoon onsets. The distinct slopes between El Niño/La Niña years can be attributed to the different types of QSAR pathways, as discussed before (Figure 3a/3b). Our analysis reveals that ENSO has an indirect influence on monsoon onset date, by determining the lead time between dateline crossing of the Pacific QSAR and monsoon onset. During an El Niño, the linear regression indicates that with high confidence, the Pacific QSAR dateline crossing (22 March) occurs 40 days before EASM onset and 25 days before onset when it occurs on 16 May. During La Niña years, the linear regression indicates 50-day lead time between dateline crossing and EASM onset when the former occurs on 22 March; however, there is zero lead time when the dateline crossing occurs on 28 May. As for non-ENSO years (9 over 39 years, as shown in Figure S6a), the trend of dateline crossing leading EASM onset is insignificant.

The influence of ENSO on EASM onset is unable to fully explain year-to-year varability of EASM onset as indicated by the moderate linear correlation coefficients (Ding et al., 2008; Zhou \& Chan, 2007), probably because the influence itself changes year to year (Chou et al., 2009) or other climate factors also influence the monsoon onset (Kosaka et al., 2013). Our precursor of the EASM due to the seasonal pathway of the Pacific QSARs defines two distinct slopes of linear regression with higher correlation coefficients, although we have yet to establish the cause of a QSAR and how it impacts the EASM.

\section{QSAR: The Quasi-Stationary Wave-Breaking Front}

We now move on to discuss interaction of QSARs with westerly synoptic waves that are representative of the westerly signals in Hovmöller diagrams from Figure 2 as we described in section 2 and speculate on the potential mechanism that halts those waves. Westerly synoptic waves typically initiate downstream of the Tibetan Plateau and Rocky Mountains but grow in amplitude as they propagate to the east, eventually breaking and decaying in about 8 days (Thorncroft et al., 1993). The wave breaking occurs when westerly synoptic waves fold back on themselves, and this also causes the associated atmospheric rivers to be deformed (Payne \& Magnusdottir, 2014). After traveling to the quasi-stationary zones marked by the QSARs, waves become 


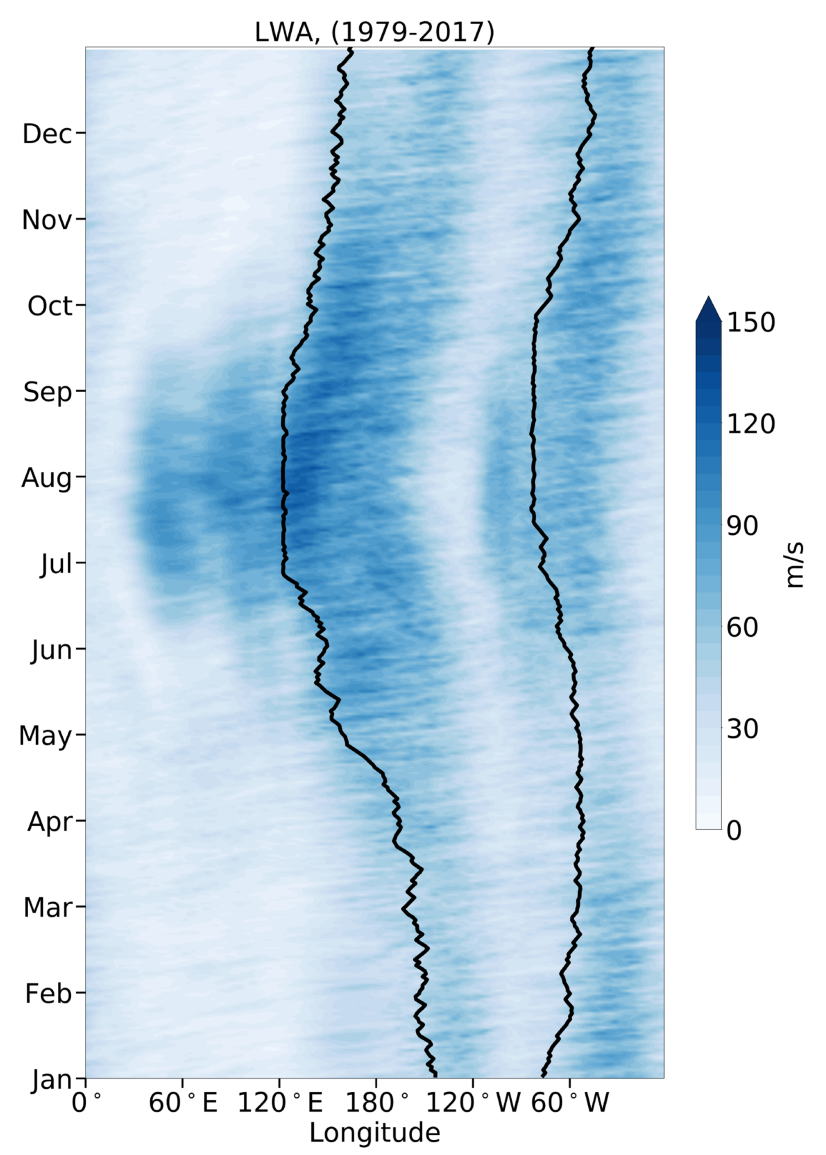

Figure 4. The Hovmöller diagram of daily mean climatology local wave activity (LWA), a measure of the nonlinearity of waves, at $30^{\circ} \mathrm{N}$ with the addition of quasi-stationary part of atmospheric rivers pathways (black curves).

stationary, continue growing, and finally break. This is verified by the Hovmöller diagram (Figure 4) of local wave activity (LWA), which quantifies wave breaking as a measure of zonal anomalies of potential vorticity at $250 \mathrm{mb}$ (see details in Huang \& Nakamura, 2016). Although LWA is widely distributed, an enhanced area of LWA occurs on the downstream side of the QSARs, consistent with them being preferred locations of wave breaking.

We speculate the zonally and seasonally decaying Pacific jet stream, which decreases from west to east along $30^{\circ} \mathrm{N}$ and generates the QSAR. The decrease in jet speed probably comes from the zonally varying meridional temperature gradient in the Pacific/Atlantic; weaker meridional temperature gradients in the Eastern Pacific/Atlantic cause the zonal jet to weaken. Additionally, the Pacific/Atlantic jet stream evolves seasonally, from being strong and extended into the Eastern Pacific/Atlantic in winter to being weak, contracted, and further north in summer. The jet carries westerly synoptic waves forming from the most unstable region downstream of the Tibetan Plateau and Rocky Mountains. These westerly waves encounter decreasing winds as they propagate downstream, becoming stationary when the background jet speed equals the phase speed of the waves, which causes them to then break (Thorncroft et al., 1993). As the Pacific jet weakens and contracts in summer, westerly waves break closer to East Asia/North America, and this causes the QSAR to move closer to the coast. During El Niño (La Niña) periods, the warming (cooling) east Pacific strengthens (weakens) the east Pacific jet and consequently pushes the QSAR further east (west) during winter as observed in Figure 3a/3b. Hence, El Niño (La Niña) QSARs travel longer (shorter) distances, and these probably cause different slopes of linear regressions as shown in Figure 3c/3d. However, this speculation still requires further theoretical support to explain the presence of the linear relationship between 40-mm exceedance date and dateline crossing date. 


\section{Summary and Conclusions}

In this study, we discuss the discovery of localized, quasi-stationary zones of atmospheric rivers and develop a tracking algorithm to identify QSAR pathways. The Pacific QSAR has predictive skill for EASM onsets as the CWV of Pacific QSARs first exceeds $40 \mathrm{~mm}$ during strong ENSO periods. We also speculate on origin of QSAR dynamics from the perspective of synoptic wave breaking. We suspect that the seasonal contractions of zonally decaying jet streams form quasi-stationary zones of atmospheric rivers (QSARs). This speculation needs to be tested by climate model simulations and quasi-geostrophic theories to explore QSAR formation mechanisms with different migrating speeds during ENSO. We plan to extend the study to a wider range of latitudes given the presence of QSAR features in $25-40^{\circ} \mathrm{N}$ and to include an improved tracking algorithm that better identifies QSAR pathways.

The evidence for repeating QSARs in CWV Hovmöller diagrams for the past 39 years shows the climate components of synoptic atmospheric rivers. The fact that the Pacific QSAR dateline crossing date leads EASM onset implies that it could be strongly affected by the zonal and seasonal migrations of QSARs. The strong predictive skill of EASM onset during strong ENSO indicates the predictability of year-to-year variability of EASM onset and also shows the power of a CWV-based monsoon proxy to better identify details of longitudinal-temporal structures of the EASM. This study opens a new prospective that incorporate midlatitude wave dynamics in the description of EASM onset mechanisms instead of more conventional sea breeze and meridional migrations of ITCZ.

\section{Appendix A: Method for Identifying QSAR Pathways}

Given the possibility of QSARs as monsoon predictors, one requisite task is to identify the pathway of QSAR propagations. However, due to the noisiness of raw data, a simple tracking of the local maximum CWV in each ocean basin is discontinuous and fails to represent smooth QSAR pathways that the eye easily picks out in Figure 1a/1b. Therefore, we develop a technique to generate continuous pathways of QSARs. First, a QSAR begins at the location with maximum CWV inside Pacific $\left(120^{\circ} \mathrm{E}-120^{\circ} \mathrm{W}\right)$ and Atlantic $\left(90-10^{\circ}\right.$ W) on 1 January. Each subsequent day, a QSAR is defined to be at a neighboring location where the CWV is locally maximal. The neighbor location is chosen at the appropriate window of a longitudinal range. A narrow window size is inflexible enough to follow QSARs, but a wide window captures large amounts of synoptic structures of ARs.

We test several pairs of window sizes that generate QSAR pathways (as shown in Figure S1a) and list the percentage of days with local maxima occurring at the window edge in Table S1, to find the window sizes that better identify reasonable QSAR pathways for this study. A reasonable percentage is the window that is wide enough to not have too many edge maxima while minimizing the number of jumps due to synoptic events; we settled on $\sim 50 \%$. Hence, we choose $6.75^{\circ} \mathrm{W}-5.25^{\circ} \mathrm{E}$ of the Pacific window and $3.75^{\circ} \mathrm{W}-4.5^{\circ} \mathrm{E}$ of Atlantic window. To evaluate the significance of those pathways, we generate 1,000 pathways (as shown in Figure S1b) by adding white noise to the raw CWV with an amplitude ratio of 0.4 relative to the variance of the data and plot their ensemble averages. The chosen noise ratio has been tested to optimize identification of QSAR pathways and contains the same order of standard deviations ( $\sim 10^{\circ}$ of longitudes $)$ due to the different window sizes.

The majority of QSARs stay at the same longitude during summertime (July-September), because CWV loses its continuity due to large topography, especially in East Asia. Therefore, when calculating a QSAR pathway, we exclude the East Asian continent (west of $123^{\circ} \mathrm{E}$ ) to prevent the Pacific QSAR from staying in East Asia after monsoon retreats. The 1-month convergence of Pacific QSARs beginning at each longitude of $150^{\circ} \mathrm{E}-120^{\circ} \mathrm{W}$ on 1 January (as shown in Figure S1c) indicates that the tracking algorithm could tolerate a certain range of different initial locations. QSAR pathways on 5-/39-year climatological CWV could be acquired by applying the same algorithm on daily climatological average of CWV. QSAR pathways are unnecessary to be closed at the start/end date (1 January/31 December) for individual year and ENSO climatology but need to be closed at the start/end date for 5- and 39-year climatology. To ensure an enclosed QSAR pathway, we set two consecutive climatological annual cycles, initiate the tracking algorithm on 15 January in the second year, run for both subsequent/preceding days forward/backward to deep summers, and form the annual cycle of a QSAR pathway between two summers. 


\section{Acknowledgments}

H.-I. L. was supported in part by a Government scholarship to study abroad (GSSA) by Ministry of Education, Taiwan, Republic of China, Furukawa Fellowship and Dissertation Year Fellowship from Department of Atmospheric and Oceanic Sciences, UCLA. J. L. was supported by a Chancellor's postdoctoral fellowship. A. T. acknowledges support from a NSF CAREER award and by the "Laboratoired'Excellence" LabexMER (ANR-10-LABX-19) and the French government ("Investissements d'Avenir").We thank Clare S.-Y. Huang of Department of Geophysics, University of Chicago for supporting python package and validating the analysis of local wave activity. ERA-Interim reanalysis data is provided by ECMWF (https://ecmwf int/en/research/climate-reanalysis/ era-interim).

\section{References}

Boos, W. R., \& Kuang, Z. (2010). Dominant control of the South Asian monsoon by orographic insulation versus plateau heating. Nature, 463(7278), 218-222.

Bordoni, S., \& Schneider, T. (2008). Monsoons as eddy-mediated regime transitions of the tropical overturning circulation. Nature Geoscience, 1(8), 515-519.

Chou, C., Huang, L.-F., Tu, J.-Y., Tseng, L., \& Hsueh, Y.-C. (2009). El Niño impacts on precipitation in the Western North Pacific-East Asian sector. Journal of Climate, 22(8), 2039-2057.

Chou, C., \& Neelin, J. D. (2003). Mechanisms limiting the northward extent of the northern summer monsoons over North America, Asia, and Africa. Journal of Climate, 16(3), 406-425.

Dee, D. P., Uppala, S., Simmons, A., Berrisford, P., Poli, P., Kobayashi, S., et al. (2011). The ERA-Interim reanalysis: Configuration and performance of the data assimilation system. Quarterly Journal of the Royal Meteorological Society, 137(656), 553-597.

Ding, Y., Wang, Z., \& Sun, Y. (2008). Inter-decadal variation of the summer precipitation in East China and its association with decreasing Asian summer monsoon. Part I: Observed evidences. International Journal of Climatology, 28(9), 1139-1161.

Emanuel, K. A. (1995). On thermally direct circulations in moist atmospheres. Journal of the Atmospheric Sciences, 52(9), 1529-1534.

Fang, M., \& Tung, K. K. (1999). Time-dependent nonlinear Hadley circulation. Journal of the Atmospheric Sciences, 56(12), $1797-1807$.

Faulk, S., Mitchell, J., \& Bordoni, S. (2017). Effects of rotation rate and seasonal forcing on the ITCZ extent in planetary atmospheres Journal of the Atmospheric Sciences, 74(3), 665-678.

Geen, R., Lambert, F., \& Vallis, G. (2018). Regime change behavior during Asian monsoon onset. Journal of Climate, 31(8), 3327-3348.

Huang, C. S., \& Nakamura, N. (2016). Local finite-amplitude wave activity as a diagnostic of anomalous weather events. Journal of the Atmospheric Sciences, 73(1), 211-229.

Ju, J., \& Slingo, J. (1995). The Asian summer monsoon and ENSO. Quarterly Journal of the Royal Meteorological Society, 121(525), $1133-1168$.

IPCC (2013). Summary for Policymakers. In T. F. Stocker et al. (Eds.), Climate Change 2013: The Physical Science Basis. Contribution of Working Group I to the Fifth Assessment Report of the Intergovernmental Panel on Climate Change (pp. 1-30). Cambridge, United Kingdom and New York, NY, USA: Cambridge University Press. https://doi.org/10.1017/CBO9781107415324.004

Kamae, Y., Mei, W., \& Xie, S.-P. (2017). Climatological relationship between warm season atmospheric rivers and heavy rainfall over East Asia. Journal of the Meteorological Society of Japan Series II, 95, 411-431.

Kamae, Y., Mei, W., Xie, S.-P., Naoi, M., \& Ueda, H. (2017). Atmospheric rivers over the northwestern Pacific: Climatology and interannual variability. Journal of Climate, 30(15), 5605-5619.

Kelly, P., \& Mapes, B. (2013). Asian monsoon forcing of subtropical easterlies in the Community Atmosphere Model: Summer climate implications for the Western Atlantic. Journal of Climate, 26(9), 2741-2755.

Kosaka, Y., Xie, S.-P., Lau, N.-C., \& Vecchi, G. A. (2013). Origin of seasonal predictability for summer climate over the Northwestern Pacific. Proceedings of the National Academy of Sciences, 110(19), 7574-7579.

Lau, N.-C., \& Nath, M. J. (2003). Atmosphere-ocean variations in the Indo-Pacific sector during ENSO episodes. Journal of Climate, 16(1), $3-20$.

Li, X., \& Zhou, W. (2012). Quasi-4-yr coupling between El Niño-Southern Oscillation and water vapor transport over East Asia-wnp. Journal of Climate, 25(17), 5879-5891.

Li, C., Zuo, Q., Xu, X., \& Gao, S. (2016). Water vapor transport around the Tibetan Plateau and its effect on summer rainfall over the Yangtze River Valley. Journal of Meteorological Research, 30(4), 472-482.

Lindzen, R. S., \& Hou, A. V. (1988). Hadley circulations for zonally averaged heating centered off the equator. Journal of the Atmospheric Sciences, 45(17), 2416-2427.

Mundhenk, B. D., Barnes, E. A., \& Maloney, E. D. (2016). All-season climatology and variability of atmospheric river frequencies over the North Pacific. Journal of Climate, 29(13), 4885-4903.

Pan, C., Zhu, B., Gao, J., \& Kang, H. (2017). Source apportionment of atmospheric water over East Asia-A source tracer study in CAM5. 1. Geoscientific Model Development, 10(2), 673-688.

Payne, A. E., \& Magnusdottir, G. (2014). Dynamics of landfalling atmospheric rivers over the North Pacific in 30 years of MERRA reanalysis. Journal of Climate, 27(18), 7133-7150.

Peters, O., \& Neelin, J. D. (2006). Critical phenomena in atmospheric precipitation. Nature Physics, 2(6), 393.

Plumb, R. A., \& Hou, A. Y. (1992). The response of a zonally symmetric atmosphere to subtropical thermal forcing: Threshold behavior. Journal of the Atmospheric Sciences, 49(19), 1790-1799.

Privé, N. C., \& Plumb, R. A. (2007). Monsoon dynamics with interactive forcing. Part II: Impact of eddies and asymmetric geometries. Journal of the Atmospheric Sciences, 64(5), 1431-1442.

Renhe, Z. (2001). Relations of water vapor transport from Indian monsoon with that over East Asia and the summer rainfall in China. Advances in Atmospheric Sciences, 18(5), 1005-1017.

Schneider, T., \& Bordoni, S. (2008). Eddy-mediated regime transitions in the seasonal cycle of a Hadley circulation and implications for monsoon dynamics. Journal of the Atmospheric Sciences, 65(3), 915-934.

Seth, A., Rauscher, S. A., Biasutti, M., Giannini, A., Camargo, S. J., \& Rojas, M. (2013). CMIP5 projected changes in the annual cycle of precipitation in monsoon regions. Journal of Climate, 26(19), 7328-7351.

Shaw, T. A., \& Boos, W. R. (2012). The tropospheric response to tropical and subtropical zonally asymmetric torques: Analytical and idealized numerical model results. Journal of the Atmospheric Sciences, 69(1), 214-235.

Shaw, T. A., \& Voigt, A. (2016). Understanding the links between subtropical and extratropical circulation responses to climate change using aquaplanet model simulations. Journal of Climate, 29(18), 6637-6657.

Tanaka, M. (1997). Interannual and interdecadal variations of the western North Pacific monsoon and Baiu rainfall and their relationship to the ENSO cycles. Journal of the Meteorological Society of Japan Series II, 75(6), 1109-1123.

Thorncroft, C., Hoskins, B., \& McIntyre, M. (1993). Two paradigms of baroclinic-wave life-cycle behaviour. Quarterly Journal of the Royal Meteorological Society, 119(509), 17-55.

Walker, C. C., \& Schneider, T. (2006). Eddy influences on Hadley circulations: Simulations with an idealized GCM. Journal of the atmospheric sciences, 63(12), 3333-3350.

Wang, B. (2002). Rainy season of the Asian-Pacific summer monsoon. Journal of Climate, 15(4), 386-398

Wang, B., Xiang, B., \& Lee, J.-Y. (2013). Subtropical high predictability establishes a promising way for monsoon and tropical storm predictions. Proceedings of the National Academy of Sciences, 110(8), 2718-2722. 
Wang, B., Zhang, Y., \& Lu, M. (2004). Definition of South China Sea monsoon onset and commencement of the East Asia summer monsoon. Journal of Climate, 17(4), 699-710.

Webster, P. (1987). The elementary monsoon. Monsoons Edited by J. S. Fein, \& P. L. Stephens. Hoboken, NJ: John Wiley and Sons.

Webster, P., \& Fasullo, J (2003). Encyclopedia of atmospheric sciences 1370-1385. New York: Academic.

Wu, R., \& Wang, B. (2000). Interannual variability of summer monsoon onset over the western North Pacific and the underlying processes. Journal of climate, 13(14), 2483-2501.

Wu, B., Zhou, T., \& Li, T. (2009). Seasonally evolving dominant interannual variability modes of East Asian climate. Journal of Climate, 22(11), 2992-3005.

Xie, S.-P., \& Saiki, N. (1999). Abrupt onset and slow seasonal evolution of summer monsoon in an idealized GCM simulation. Journal of the Meteorological Society of Japan Series II, 77(4), 949-968.

Yao, S., Huang, Q., Zhang, Y., \& Zhou, X. (2013). The simulation of water vapor transport in East Asia using a regional air-sea coupled model. Journal of Geophysical Research: Atmospheres, 118, 1585-1600. https://doi.org/10.1002/jgrd.50089

Yong, L., \& Huang, R. (2019). Linkages between the south and east Asian monsoon water vapor transport during boreal summer. Journal of Climate, 32, 4509-4524.

Zhang, Y., Li, T., Wang, B., \& Wu, G. (2002). Onset of the summer monsoon over the Indochina Peninsula: Climatology and interannual variations. Journal of Climate, 15(22), 3206-3221.

Zhou, W., \& Chan, J. C. (2007). ENSO and the South China Sea summer monsoon onset. International Journal of Climatology, 27(2), 157-167. 